\title{
PRODUTORES RURAIS EM LOCALIDADES DO INTERIOR PAULISTA COMO TUPÃ E A LOGÍSTICA REVERSA DE DEVOLUÇÃO DAS EMBALAGENS VAZIAS DE AGROTÓXICOS
}

\author{
Mauricio Dias Marques ${ }^{1}$ \\ Silvia Cristina Vieira ${ }^{2}$
}

\begin{abstract}
RESUMO: O objetivo geral desta pesquisa consistiu em procurar entender como a política pública da logística reversa das embalagens vazias de agrotóxicos funciona na prática, num recorte geográfico do interior paulista, no município de Tupã, na forma da legislação vigente. Os objetivos específicos tratam de identificar as políticas públicas por meio da legislação que disciplina a logística reversa de devolução de embalagens vazias de agrotóxicos e coletar informações do procedimento do início da cadeia logística reversa, junto ao produtor rural, que proporciona start ao processo de retorno das embalagens à indústria fabricante e, assim, contribui com sua ação para a preservação do meio ambiente e desenvolvimento sustentável. Para o desenvolvimento deste artigo, adotou-se metodologia qualitativa, numa pesquisa de campo, com objetivo exploratório que revelou a dicotomia de uma robusta legislação que ampara a logística reversa de embalagens vazias de agrotóxicos, enquanto que seu cumprimento demonstrou-se um desafio, com pouco incentivo, identificando falhas nas governanças que não demonstram alinhamento à norma formal para promover o cumprimento da lei e a conscientização dos produtores rurais.
\end{abstract}

PALAVRAS-CHAVE: Logística Reversa. Meio ambiente. Políticas públicas.

\section{FARMERS IN PLACES OF INTERIOR HOW PAULISTA TUPÃ AND RETURN REVERSE LOGISTICS OF EMPTY CONTAINERS OF PESTICIDE}

\begin{abstract}
The overall objective of this research was to try to understand how the public policy of reverse logistics of empty pesticide containers works in practice, in one geographic cut in the interior of the state of São Paulo, the city of Tupa, according to the law. The specific objectives try to identify public policies through legislation which governs the reverse logistics of return of empty pesticide containers and collect information from the beginning of the reverse logistics chain procedure by the farmers, which provides start of the process of return to industry and thus contribute with its action for the preservation of the environment and sustainable development. To develop this paper, we adopted qualitative methodology, a field research with an exploratory objective which revealed the dichotomy of a robust legislation that supports the

\footnotetext{
${ }^{1}$ Mestrando em agronegócio e desenvolvimento, especialista em Direito e em Administração, graduado em Direito, Administração e Ciências Contábeis. Membro do Grupo de Pesquisa PGEA, UNESP. E-mail: mdmarques1985@gmail.com.

${ }^{2}$ Mestranda em agronegócio e desenvolvimento, especialista em gestão do agronegócio e HIPOA/Vigilância sanitária de alimentos, graduada em medicina veterinária. Membro do Projeto de Extensão CoDAF e dos Grupos de Pesquisa CEPEAGRO e PGEA. UNESP. Email.tinavieiragomes@hotmail.com.br
} 


\section{ANAP $B_{\text {rasil }}$}

reverse logistics of empty pesticide containers, while your compliance proved to be a challenge, with little incentive, identifying gaps in governances what not demonstrate alignment to formal standard for promoting the law enforcement and the awareness of farmers.

KEYWORDS: Reverse logistic. Environment. Public policy.

\section{AGRICULTORES EN LUGARES DE INTERIOR COMO PAULISTA TUPA Y VUELTA ATRÁS LOGÍSTICA DE CONTENEDORES VACIOS DE PESTICIDA}

RESUMÉN: El objetivo general de esta investigación fue tratar de entender cómo la política pública de la logística inversa de los envases vacíos de plaguicidas funciona en la práctica, un recorte geográfico en el interior de la ciudad de Tupa, de acuerdo con la ley. Los objetivos específicos tratan de identificar las políticas públicas a través de la legislación que regula el retorno de logística inversa de los envases vacíos de plaguicidas y recopilar información desde el inicio del procedimiento de la cadena logística inversa por lo agricultor, que proporciona iniciar el proceso de retorno de fabricante de envases para la industria y por lo tanto contribuye su parte a la preservación del medio ambiente y el desarrollo sostenible. Para desarrollar este trabajo, hemos adoptado la metodología cualitativa, una investigación de campo con un objetivo de exploración que reveló la dicotomía de una legislación robusta que soporta la logística inversa de los envases vacíos de plaguicidas, mientras que el cumplimiento resultó ser un reto, con pocos incentivos, la identificación de lagunas en gobernaciones no demuestra la alineación con la norma oficial para la promoción del estado de derecho y la concienciación de los agricultores.

PALABRAS CLAVE: Logística inversa. Medio Ambiente. Las políticas públicas.

\section{INTRODUÇÃO}

A utilização de defensivos agrícolas trouxe grande impulso para a produção agrícola a partir da década de 1920. No Brasil, o uso de agrotóxicos tornou-se intenso a partir da década de 1960. Mas isso gera grave problema de saúde pública, demandando a implantação de um sistema de vigilância da saúde de populações expostas a agrotóxicos (OPAS / OMS, 2010).

O Brasil encontra-se entre os principais consumidores mundiais de defensivos agrícolas, com maior utilização na agricultura. Discussões abordam vantagens pelos retornos econômicos e agronômicos que os defensivos agrícolas proporcionam ao produtor rural e desvantagens pela degradação ambiental e risco à saúde humana. Em relação às suas embalagens, existem restrições legais relacionadas ao meio ambiente e aos fatores econômicos (SHIBAO; MOORI; SANTOS, 2010).

Revista Científica ANAP Zrasd, v. 8, n. 11, 2015, p. 30-46. 
Conforme a norma brasileira NBR 10.004 aprovada pela ABNT no ano de 2004, as embalagens vazias de agrotóxicos enquadram-se na categoria de resíduos perigosos pelo seu potencial de toxicidade e contaminação, já que geralmente contêm resíduos do produto ativo. Segundo Cometti e Alves (2010), se descartadas no meio ambiente podem contaminar o solo e lençóis freáticos; se reutilizadas como utensílios domésticos para condicionar água e alimentos, podem provocar contaminação humana.

Há uma tendência, no cenário mundial, de transferência das responsabilidades sobre coleta, transporte e destinação final das embalagens e outros resíduos, dos governos para as cadeias produtivas. Segundo apanhado feito por Cometti e Alves (2010), a legislação na Europa é avançada no sentido de exigir que os fabricantes recolham as embalagens e a Alemanha foi $o$ primeiro país a adotar essa pratica, criando redes logísticas em torno de fluxos reversos. Nos Estados Unidos a legislação de grande parte dos estadosmembros incentiva o uso de produtos fabricados com materiais reciclados, através de sistemas tributários especiais. No Brasil, a responsabilidade é solidária entre aqueles que direta e indiretamente praticaram a conduta lesiva ao meio ambiente.

Uma forma de implantar essa responsabilidade solidária é a transferência das embalagens do consumo ao produtor dos agrotóxicos, por meio da logística reversa, conforme estabelecido na Política Nacional de Resíduos Sólidos - PNRS apontada na Lei 12.305/2010, regulamentada pelo Decreto 7.404/2010 e sistematizada na Lei dos Agrotóxicos (Lei 9.974/2000), regulamentada pelo Decreto 4.074/2002 (BRASIL, 2010; 2000; 2002).

Segundo a Política Pública vigente, a Lei dos Agrotóxicos impõe responsabilidades e competências divididas entre todos os agentes atuantes no uso dos defensivos agrícolas. Ao produtor rural (que é aquele que utiliza o agrotóxico como consumidor final) coube a responsabilidade da tríplice lavagem e devolução das embalagens pós-consumo; aos comerciantes, a responsabilidade de dispor de local adequado para recebimento das 


\section{ANAP $B_{\text {rasil }}$ \\ ISSN 1904-3240 \\ V. 8, n. 11}

embalagens e/ou indicar nas notas fiscais de venda os locais de devolução; ao fabricante, a responsabilidade de recolher e dar a destinação final adequada às embalagens; e ao governo, a responsabilidade de fiscalizar e promover, junto com os fabricantes, a orientação técnica e educação ambiental.

Todas essas ações de responsabilidades se desenvolvem por meio da logística reversa, com início no produtor rural.

\section{OBJETIVO}

O objetivo geral da presente pesquisa consiste em procurar entender se a logística reversa das embalagens vazias de agrotóxicos funciona na prática, no interior paulista, no município de Tupã, conforme determinação da legislação vigente.

Como objetivos específicos elencam-se:

- Identificar as políticas públicas por meio da legislação que disciplina a logística reversa de devolução de embalagens vazias de agrotóxicos;

- Coletar informações do procedimento do início da cadeia logística reversa, junto ao produtor rural, que deve dar início ao retorno das embalagens à indústria fabricante e, assim, contribuir na preservação do meio ambiente e desenvolvimento sustentável.

\section{METODOLOGIA}

Com relação à abordagem, utiliza-se a metodologia qualitativa, na qual o investigador entra em contato direto com o indivíduo ou grupos humanos, com o ambiente e com a situação que está sendo investigada, permitindo um contato de perto com os informantes (MARCONI; LAKATOS, 2004).

Quanto ao objetivo, trata-se de uma pesquisa descritiva e exploratória. Caracteriza-se como exploratória, pois tem por objetivo familiarizar-se com o fenômeno, obtendo uma nova percepção do mesmo. E descritiva, por realizar narrativas das situações e buscar descobrir as relações existentes entre os elementos que compõem a pesquisa. Além disso, flexibiliza o planejamento 


\section{ANAP $B_{\text {rasil }}$ \\ ISSN 1904-3240 \\ V. 8, n. 11}

para possibilitar a consideração dos mais diversos aspectos do problema (CERVO; BERVIAN, 2003).

A técnica de coleta de dados harmoniza vários instrumentos. Em primeiro momento, realizou-se uma pesquisa bibliográfica sobre o trâmite da logística reversa das embalagens vazias de agrotóxicos, a disposição legal e obstáculos encontrados pelo produtor rural. Na sequência, ocorreu uma pesquisa documental com base nas políticas públicas constantes na legislação contemporânea sobre o tema abordado.

Em segundo momento, durante atividade de campo, a coleta de dados deu-se por meio de aplicação de formulários semiestruturados junto a 20 produtores rurais da Estância Turística de Tupã, interior do estado de São Paulo, nos meses de abril a maio de 2015, onde se buscou informações sobre sua predisposição em devolver as embalagens, como estabelecido na legislação e os gaps encontrados para que a devolução ocorra. A análise desta pesquisa de campo considerou os resultados dos formulários sobrepostos ao conteúdo bibliográfico e à legislação pesquisada.

\section{A LOGÍSTICA REVERSA E AS EMBALAGENS DE AGROTÓXICOS}

A Política Nacional de Resíduos Sólidos - Lei 12.305/2010, estabeleceu como instrumento de desenvolvimento econômico e social a implantação de sistemas de logística reversa, imputando a responsabilidade do pós-consumo aos fabricantes, importadores, distribuidores, comerciantes e consumidores (MOURÃO e SEO, 2012).

Como definido no inciso XII do artigo 3ํㅡ dessa lei "logística reversa é o instrumento de desenvolvimento econômico e social caracterizado por um conjunto de ações, procedimentos e meios destinados a viabilizar a coleta e a restituição dos resíduos sólidos ao setor empresarial, para reaproveitamento, em seu ciclo ou em outros ciclos produtivos, ou outra destinação final ambientalmente adequada" (BRASIL, 2010). 


\section{ANAP $B_{\text {rasil }}$ \\ ISSN 1904-3240 \\ V. 8, n. 11}

\section{REVISTA}

Freitas, Hoppe e Murini (2015), colocam que a logística reversa é um instrumento ligado ao consumo sustentável, eis que propicia retorno dos produtos ao processo produtivo, tornando possível a transformação em matéria-prima. É importante a logística reversa das embalagens de defensivos agrícolas, pois diminui o "lixo" nas propriedades rurais, que pode impactar significativamente o meio ambiente causando danos nocivos à saúde humana e à natureza.

Para Sehnen, Simioni e Chiesa (2009), o conceito de logística leva a uma visão da cadeia completa no processo de suprimento de materiais, envolvendo desde as atividades do início até ao final, tornando-se chave de muitos negócios.

Por sua vez, a logística reversa completa o caminho para reciclagem dos objetos "sem valores" associados ao produto principal e as empresas têm encontrado oportunidades de recuperar os custos de produção, ganhando dinheiro. A logística envolve a cadeia de produção, da matéria-prima até o consumidor final; a logística reversa inicia-se no ponto de consumo e termina na origem. (SEHNEM, SIMIONI E CHIESA, 2009)

Segundo Souza e Gebler (2013), entre os principais fatores determinantes do destino final das embalagens vazias de agrotóxicos encontrase o tipo de material que as constitui e sua periculosidade ao meio ambiente, determinada em função da possibilidade de realização do processo de tríplice lavagem no momento de preparo da calda, indicada pela Norma 10.004 da ABNT (2004), com duas classes de resíduos: I - perigosos; II - não perigosos. As embalagens rígidas vazias de agrotóxicos, que podem ser objeto da tríplice lavagem, são classificadas como resíduo não perigoso (classe II) para fins de manuseio, transporte e armazenagem. As embalagens que acondicionam produtos na forma sólida (em grânulo ou pó), destinados ao tratamento de sementes ou cuja forma de aplicação exija volume ultra-baixo de água (menos de 20 litros por hectare) impedindo a tríplice lavagem, pertencem à classe 1 . 


\title{
ANAP

Para chegar ao destino final há que se percorrer a logística reversa. A logística reversa das embalagens vazias de agrotóxicos, especificamente, é determinada pela legislação, como se pode observar nos parágrafos $2^{\circ}$ e $5^{\circ}$ do artigo $6^{\circ}$ transcritos abaixo, da Lei 7.802/89, alterada pela Lei 9.974/2000:

\begin{abstract}
$\S 2^{\circ}$ Os usuários de agrotóxicos, seus componentes e afins deverão efetuar a devolução das embalagens vazias dos produtos aos estabelecimentos comerciais em que foram adquiridos, de acordo com as instruções previstas nas respectivas bulas, no prazo de até um ano, contado da data de compra, ou prazo superior, se autorizado pelo órgão registrante, podendo a devolução ser intermediada por postos ou centros de recolhimento, desde que autorizados e fiscalizados pelo órgão competente.

$\S 5^{\circ}$ As empresas produtoras e comercializadoras de agrotóxicos, seus componentes e afins, são responsáveis pela destinação das embalagens vazias dos produtos por elas fabricados e comercializados, após a devolução pelos usuários, e pela dos produtos apreendidos pela ação fiscalizatória e dos impróprios para utilização ou em desuso, com vistas à sua reutilização, reciclagem ou inutilização, obedecidas as normas e instruções dos órgãos registrantes e sanitário-ambientais competentes (BRASIL, 2000).
\end{abstract}

De acordo com Carboni, Sato e Moori (2005) o processo da logística reversa das embalagens vazias inicia-se no agricultor, que tem a obrigação legal de efetuar, nas embalagens, uma tríplice lavagem ou lavagem sob pressão e devolvê-las no prazo de um ano após a compra ou de seis meses após o vencimento do produto. A lavagem sob pressão é utilizada no caso de embalagens rígidas e metálicas, enquanto que as flexíveis (sacos de papel, aluminizados e polietileno de baixa densidade) tem como destino a incineração.

Conforme Boldrin et al. (2007, p.36), as seguintes etapas devem ser seguidas para que a coleta de embalagens vazias de agrotóxicos no campo tenha êxito: "produtor $\rightarrow$ incentivos à devolução $\rightarrow$ tríplice lavagem $\rightarrow$ transporte da zona rural até o centro coletor $\rightarrow$ recebimento no centro coletor $\rightarrow$ armazenamento neste centro até determinado nível de estoque $\rightarrow$ recolhimento por parte da industria para ser dada a destinação final".

Sehnem, Simioni e Chiesa (2009), registram que o processo pelo qual se desencadeia o fluxo de reciclagem de embalagens de agrotóxicos vazias é o 


\section{ANAP $B_{\text {rasil }}$ \\ ISSN 1904-3240 \\ V. 8, n. 11}

\section{REVISTA}

seguinte: Compra do produto; Aplicação na lavoura; Lavagem da embalagem; Inutilização da embalagem; Devolução na unidade de recebimento; Prensagem da embalagem; Transporte para o destino final; Etapa da reciclagem; Produção do artefato.

Continuam esses mesmos autores a ponderar que, com o destino correto das embalagens, para um lugar adequado, deixam de ser jogadas a céu aberto, no meio ambiente. Assim, há benefícios proporcionados por esse tipo de logística reversa proporcionando uma melhor preservação do meio ambiente, benefícios para toda a sociedade e para as futuras gerações.

\subsection{A operacionalização prática da logística reversa com início no produtor rural}

Para Bressan et al. (2014), apesar da legislação determinar a obrigação do agricultor em devolver as embalagens pós consumo, ela não determina como será aplicada. Até o ano de 2000 não existia ainda nenhuma entidade que viabilizasse o processo de devolução das embalagens.

Com vistas a possibilitar o atendimento da exigência legal e facilitar a operacionalização da logística reversa, foi criado o INPEV (Instituto Nacional de Processamento de Embalagens Vazias).

Conforme bem explanado por Sehnem, Simioni e Chiesa (2009), o INPEV é uma entidade sem fins lucrativos, que se dedica a gerir o processo de destinação de

embalagens vazias de fitossanitários no Brasil, dar apoio e orientação à indústria, canais de distribuição e agricultores no cumprimento das responsabilidades definidas pela legislação, promover a educação e a consciência de proteção ao meio ambiente e à saúde humana e apoiar o desenvolvimento tecnológico de embalagens de agrotóxicos e afins.

Segundo Bressan et al (2014), essa organização responde pela gestão do chamado Sistema Campo Limpo, está presente em todas regiões do país e promove vários programas de educação ambiental e conscientização referente 


\section{ANAP $B_{\text {rasil }}$}

às embalagens vazias de defensivos agrícolas. Como representante da indústria, o INPEV passou a desenvolver campanhas e materiais educativos, visando estimular a realização da tríplice lavagem e a devolução das embalagens vazias pelos agricultores, indo além, ao transformar-se em disseminador da mensagem sobre a importância da preservação ambiental. $O$ Sistema Campo Limpo ganhou destaque na publicação Gestão Sustentável da Agricultura, lançada em 2013 pelo Ministério da Agricultura, Pecuária e Abastecimento. A rede é composta por quatro grupos sendo: fabricantes, comércio, poder público e os agricultores.

De acordo com Sehnem, Simioni e Chiesa (2009), o INPEV é mantido integralmente pela indústria fabricante de produtos fitossanitários e tem como principais atividades o transporte das embalagens vazias, ou seja, a logística reversa, até o destino final (reciclagem ou incineração), o fomento à criação e gerenciamento de unidades de recebimento de embalagens e a coordenação de campanhas educativas para agricultores. Está sediado em São Paulo (capital) e atua nacionalmente, exercendo importante função socioeconômica: são mais de 2500 empregos diretos, gerados por postos e centrais de recebimento de embalagens, associações de distribuidores, cooperativas, transportadoras, recicladoras e prestadores de serviço. Tem oito empresas conveniadas e ambientalmente licenciadas para a reciclagem. O número de materiais reciclados provenientes do processamento de embalagens de defensivos agrícolas chegam a aproximadamente 20 , entre os quais o conduíte, a madeira plástica, a barrica de papelão, a caixa para fiação elétrica, entre outros.

Todavia, como apontado ainda por Sehnem, Simioni e Chiesa (2009), a infraestrutura de recebimento de embalagens vazias conta com 350 unidades, com estruturas e atribuições diferenciadas, sendo a localização das centrais definida com base em critérios logísticos, preferencialmente nas proximidades dos grandes polos agrícolas, onde há maior volume de embalagens com potencial de ser devolvido. Conta ainda com recebimento itinerante ou coleta volante, sistema organizado por canais de distribuição, cooperativas, parceiros 


\section{ANAP $B_{\text {rasil }}$}

ISSN 1904-3240

V. 8, n. 11

regionais e órgãos do governo. Onde há esse serviço as operações de recebimento itinerante ocorrem em locais próximos às propriedades rurais, em caráter temporário. Os dias e os locais são normalmente divulgados com antecedência para que os agricultores possam preparar suas embalagens para a devolução.

Portanto, no âmbito formal, deixa-se transparecer que há condições de execução da logística reversa das embalagens vazias de agrotóxicos.

\section{RESULTADOS: OS PRODUTORES RURAIS, SUA RESPONSABILIDADE E O CAMINHO PRÁTICO DA LOGÍSTICA REVERSA DAS EMBALAGENS VAZIAS DE AGROTÓXICOS (PANORAMA GERAL)}

Considere-se, pois, que a política pública da logística reversa das embalagens vazias de agrotóxicos, seguindo a legislação, atribui responsabilidade ao produtor rural (usuário final do agrotóxico) e que os comerciantes contam com o apoio do INPEV para que as embalagens cheguem à industria fabricante do agrotóxico para o destino final adequado.

No entanto, essa estrutura parece não ser capaz de atender todos os pontos de propriedades rurais que utilizam os agrotóxicos, ocasionando certos problemas.

Pesquisa realizada Cometti e Alves (2010), observou que a distância das unidades de recebimento é uma das queixas mais recorrentes entre os agricultores. Muitas vezes o agricultor compra o produto em determinado estabelecimento e deve devolver a embalagem vazia em uma unidade que pode estar localizada muito distante da sua propriedade, ficando a equidade do acesso às unidades comprometida à medida que os agricultores deveriam dispor de veículo adequado, além dos custos com combustível para a devolução da embalagem vazia. Já os revendedores queixam que os fabricantes se recusam a recolher as embalagens vazias de agrotóxicos nos estabelecimentos comerciais, conforme define o art. 57 do Decreto $n^{\circ}$ 


\section{ANAP

4.074/2002, devendo eles credenciar-se a uma unidade de recebimento e pagar uma taxa fixa mensal além de outra taxa que varia conforme a quantidade de embalagens destinadas. Os fabricantes se defendem afirmando que não recolhem as embalagens nos estabelecimentos comerciais, pois estes não possuem licença ambiental para o recebimento e armazenamento temporário das embalagens vazias de agrotóxicos. Assim é que, o descumprimento do Art. 57 do Decreto n 4.074/2002 não está sendo observado pelos órgãos governamentais, responsáveis pela fiscalização do sistema de destinação final das embalagens.

Exemplificando a situação, nota-se que De Lima et al (2009), retratam que dos 135 entrevistados na região sul do Rio Grande do Sul, onde há uma central de recebimento do INPEV, $80,8 \%$ guardam as embalagens para posterior recolhimento a ser realizado pela prefeitura ou pelas revendas de agrotóxicos. Apesar da obrigatoriedade da devolução das embalagens vazias de agrotóxicos, após a tríplice lavagem, descasos e abusos foram constatados.

O IBGE investigou o meio ambiente de 5.560 municípios brasileiros, e revela as seguintes informações:

Em 2002, enquanto 600 prefeituras tinham local específico para receber embalagens de agrotóxicos, 978 descartavam tais recipientes em vazadouros a céu aberto. [...] Enquanto o vazadouro a céu aberto (ou lixão) no próprio município e a destinação mais frequente de resíduos tóxicos, entre os municípios do Norte $(68 \%)$, Nordeste $(57 \%)$ e Centro-Oeste (44\%), o destino não especificado e mais comum nos municípios do Sul (45\%) e Sudeste (33\%). É possível que esta elevada proporção de municípios que não especificam os destinos dos resíduos tóxicos deva-se a desinformacão ou a falta de um plano de gestão de resíduos, uma vez que a destinação de resíduos é responsabilidade do gerador, conforme a Lei 6438/81. [...] 978 municípios jogam embalagens de agrotóxicos em vazadouros a céu aberto. [...] Embora seja determinado por lei (decreto no 4.074, de 4/1/2002), o descarte seguro das embalagens vazias de agrotóxicos não é observado em todo o Pais: 996 municípios destinam as embalagens para posto de coleta em outro município, e 978 descartavam recipientes em vazadouro a céu aberto. No entanto, observa-se uma concentração de postos de recebimento de embalagens vazias nas principais áreas agrícolas do Pais, apontando uma certa adequação à legislação vigente.

Em todo o Pais, 600 municípios informaram possuir posto ou central de recebimento de embalagens de agrotóxicos. O destaque foi Santa Catarina, com a maior proporção de postos de recebimento [...] Do 


\section{ANAP $B_{\text {rasil }}$ \\ ISSN 1904-3240 \\ V. 8, n. 11}

\section{REVISTA C IENTIF I CA}

total dos municípios onde há fiscalização e/ou controle do uso de agrotóxicos e fertilizantes, $61,5 \%$ incentivaram a prática de agricultura orgânica. Esse percentual para o grupo de municípios que não fiscaliza o uso de agrotóxico é de apenas 28,6\% (IBGE, 2005).

\subsection{Resultados: os produtores rurais em Tupã-SP}

No formulário aplicado com os produtores rurais constam 17 proposições (questões fechadas) em escala de Lickert (com 5 valores em escala de importância) e 02 questões abertas. Buscou-se informações sobre o comportamento dos mesmos ante a legislação do retorno das embalagens vazias de agrotóxicos. Para este artigo, serão tratados os resultados obtidos relativamente a 04 questões fechadas e uma questão aberta, a saber:

Questões fechadas:

P-08 - Sempre devolvo as embalagens no endereço indicado na nota fiscal de compra.

P-12 - Sempre faço a devolução das embalagens vazias nos revendedores onde compro.

P-15 - Recebo com regularidade fiscalização sobre o armazenamento, transporte e devolução das embalagens vazias de defensivos agrícolas.

P-17 - Faço a tríplice lavagem quando prevista nas instruções das bulas.

Questão aberta:

De quanto em quanto tempo faz a devolução das embalagens?

As respostas às questões $\mathrm{P}-12$ (devolução das embalagens nos revendedores) e P-08 (devolução no endereço indicado na nota fiscal), apresentaram os seguintes resultados:

Tabela 1: Sempre faço a devolução das embalagens vazias nos revendedores onde compro

\begin{tabular}{lrr}
\hline Respostas & Frequência & Porcentagem \\
\hline 1-Discordo totalmente & 11 & $55 \%$ \\
2-Discordo & 2 & $10 \%$ \\
3-Indiferente & 5 & $25 \%$ \\
4-Concordo & 1 & $5 \%$ \\
5-Concordo totalmente & 1 & $5 \%$ \\
\hline TOTAL & 20 & $100 \%$ \\
\hline
\end{tabular}

Fonte: elaborada pelos autores (2015) 


\section{ANAP $B_{r a s i}$ \\ ISSN 1904-3240 \\ V. 8, n. 11}

Analisando os dados acima, observa-se que 11 produtores (55\%) não devolvem as embalagens, e cinco mostram-se indiferentes ao assunto.

Tabela 2: Sempre devolvo as embalagens no endereço indicado na nota fiscal

\begin{tabular}{lcr}
\hline \multicolumn{1}{c}{ Respostas } & Frequência & Porcentagem \\
\hline 1-Discordo totalmente & 4 & $20 \%$ \\
2-Discordo & 6 & $30 \%$ \\
3-Indiferente & 5 & $25 \%$ \\
4-Concordo & 2 & $10 \%$ \\
5-Concordo totalmente & 3 & $15 \%$ \\
\hline TOTAL & 20 & $100 \%$ \\
\hline
\end{tabular}

Fonte: elaborada pelos autores (2015)

Ainda, observa-se que 10 não devolvem no endereço indicado na nota fiscal de compra (50\%), e quatro ficam indiferentes à indagação. Apenas três teriam total disposição em devolver no endereço da nota fiscal, mas não o fazem efetivamente, se comparado à primeira indagação.

Então, tem-se que metade ou pouco mais da metade dos respondentes não têm tendência de efetuar a devolução das embalagens de agrotóxicos, conforme determina a legislação.

Quanto à questão P-17 (tríplice lavagem das embalagens), todos foram unânimes em concordar totalmente que fazem a lavagem, mas quase que a totalidade dos respondentes manifestaram que efetuam a lavagem para "aproveitar ao máximo o veneno" e não em virtude da consciência ambiental.

Quanto à questão P-15 (recebimento de fiscalização sobre a disposição e devolução das embalagens), todos foram unânimes em discordar totalmente, afirmando não receber fiscalização.

A questão aberta aponta o seguinte resultado: 


\section{ANAP $B_{r a s i}$ \\ ISSN 1904-3240 \\ V. 8, n. 11}

\section{REVISTA C I EN TÍlFI CA 2015}

Tabela 3: De quanto em quanto tempo faço a devolução das embalagens

\begin{tabular}{lrr}
\hline \multicolumn{1}{c}{ Respostas } & Frequência & Porcentagem \\
\hline 1 ano & 1 & $5 \%$ \\
2 anos & 1 & $5 \%$ \\
não devolve & 6 & $30 \%$ \\
nunca & 3 & $15 \%$ \\
varia & 9 & $45 \%$ \\
\hline TOTAL & 20 & $100 \%$ \\
\hline
\end{tabular}

Fonte: elaborada pelos autores (2015)

Observe-se que a análise realizada acima em relação às questões fechadas é confirmada aqui, porquanto indagados sobre a frequência do tempo de devolução, nove produtores (45\%) afirmam que não devolvem ou nunca devolveram e nove ficam na evasiva resposta de não precisar essa frequência (45\%), dizendo apenas que "varia", o que leva a perceber uma não predisposição no cumprimento da legislação.

Portanto, verifica-se muito claramente, a tendência maior a não devolução das embalagens vazias de agrotóxicos por meio da logística reversa, como determina a legislação, até porque não há fiscalização efetiva e constante por parte do Poder Público, nem mesmo conscientização nesse sentido.

\section{CONSIDERAÇÕES FINAIS}

Depreende-se de todo o estudo realizado que, embora haja uma legislação bem instrumentalizada e uma estrutura montada através do INPEV, esse instituto não consegue chegar a abranger a todos os produtores rurais em todas as localidades, já que suas unidades são poucas e distanciadas umas das outras. Por outro lado, a fiscalização efetiva é ineficiente por parte do Poder Público, nem ainda, há uma disposição das governanças municipais locais para facilitarem a coleta das embalagens e encaminhamento à unidade mais próxima do INPEV. 


\section{ANAP

Acredita-se que, se realizadas pesquisas nesse sentido em localidades diferenciadas, principalmente junto a produtores de diferentes cadeias produtivas, vai-se detectar situações semelhantes a esta aqui analisada e/ou nos exemplos trazidos aqui, advindos da literatura. Portanto, incentiva-se que novas pesquisas venham ser efetuadas e que os dados sejam utilizados como incentivo ao estabelecimento de uma política pública mais abrangente, para que se possa no mínimo contribuir para a preservação ambiental.

Torna-se evidenciado o pouco empenho das governanças para minimizar as ações antrópicas, orientar produtores rurais e proporcionar ambiente adequado para recebimento e armazenamento de embalagens vazias de agrotóxicos. O que se poderia denominar de "ecoponto", no momento encontra-se inexistente no município de Tupã e, quiçá, em tantos outros municípios do interior paulista, proporcionando um descompasso entre a legislação de logística reversa de devolução das embalagens vazias de agrotóxicos e seu cumprimento.

\section{REFERÊNCIAS BIBLIOGRÁFICAS}

Associação Brasileira de Normas Técnicas (ABNT). NBR 10.004: Resíduos Sólidos. Classificação. Rio de Janeiro: ABNT, 2004.

BOLDRIN, Vitor Paulo et al. A Gestão Ambiental e a Logística Reversa no Processo de Retorno de Embalagens de Agrotóxicos Vazias. RAI - Revista de Administração e Inovação, São Paulo, v. 4, n. 2, p. 29-48, 2007.

BRASIL. Decreto no 4.074, de 04/01/2002. Regulamenta a Lei no 7.802, de 11 de julho de 1989. Disponível em < https://www.planalto.gov.br/ccivil 03/decreto/2002/d4074.htm> Acesso em 12 mar. 2015

Decreto no 7.404, de 23/12/2010. Regulamenta a Lei no 12.305, de 02/08/2010. Disponível em www.planalto.gov.br/ccivil 03/ ato2007-2010/.../decreto/d7404.htm. Acesso em 05 set. 2014

. Lei Federal no 12.305, de 02/08/2010. Institui a Política Nacional de Resíduos Sólidos; altera a Lei ${ }^{\circ}$ 9.605, de 12 de fevereiro de 1998; e dá outras providências. Disponível em < http://www.planalto.gov.br/ccivil_03/_ato2007-2010/2010/lei//12305.htm> Acesso em 05 set. 2014

Lei no 7.802/1989, de 11/07/1989. Dispõe sobre a pesquisa, a experimentação, a produção, a embalagem e rotulagem, o transporte, o armazenamento, a comercialização, a propaganda comercial, a utilização, a importação, a exportação, o destino final dos resíduos e embalagens, o registro, a classificação, o controle, a inspeção e a fiscalização de agrotóxicos, seus componentes e 


\section{ANAP

afins, e dá outras providências. Disponível em https://www.planalto.gov.br/ccivil 03/leis/l7802.htm Acesso em 03 fev. 2015

. Lei no 9.974, de 06/06/2000. Altera a Lei oㅜ 7.802/1989, que dispõe sobre a pesquisa, a experimentação, a produção, a embalagem e rotulagem, o transporte, o armazenamento, a comercialização, a propaganda comercial, a utilização, a importação, a exportação, o destino final dos resíduos e embalagens, o registro, a classificação, o controle, a inspeção e a fiscalização de agrotóxicos, seus componentes e afins, e dá outras providências. Disponível em < http://www.planalto.gov.br/ccivil 03/leis/L9974.htm> Acesso em 12 mar. 2015

BRESSAN et al. Logística Reversa das Embalagens de Agrotóxicos: um modelo de sustentabilidade. XVI ENGEMA, 2014. Disponível em < http://www.engema.org.br/XVIENGEMA/392.pdf > Acesso em 31 ago. 215

CARBONI, Gleriani Torres; SATO, Geni Satiko; MOORI, Roberto Giro. Logística Reversa para Embalagens de Agrotóxicos no Brasil: Uma Visão sobre Conceitos e Práticas Operacionais. XLIII CONGRESSO DA SOBER "Instituições, Eficiência, Gestão e Contratos no Sistema Agroindustrial". Ribeirão Preto, 24 a 27 de Julho de 2005.

CERVO, A. L.; BERVIAN, P. A. Metodologia científica. São Paulo: Prentice Hall, 2003.

COMETTI, José Luís Said; ALVES, Isabel Teresa Gama. Responsabilização Pós-Consumo e Logística Reversa: O Caso das Embalagens de Agrotóxicos no Brasil. Revista Sustentabilidade em Debate. 2010

DE LIMA, Crislaine Alves Barcellos ; GRUTZMACHER, Douglas Daniel ; KRUGER, Leandro Rodeghiero ; GRUTZMACHER, Anderson Dionei. Diagnóstico da exposição ocupacional de agrotóxicos na principal região produtora de pêssego para indústria do Brasil. Ciencia Rural, MayJune, 2009, Vol.39, p.900

FREITAS, Michele Medianeira Martins; HOPPE, Jaqueline Hintz; MURINI, Lisandra Taschetto. A logística Reversa das Embalagens de Defensivos em uma Cooperativa Agrícola. Revista em Agronegócio e Meio Ambiente, Maringá (PR), v. 8. N. Edição Especial, p. 181-203, jan/abr. 2015

IBGE. Notícias. IBGE investiga o meio ambiente de $\mathbf{5 . 5 6 0}$ municípios brasileiros. Disponível em http://censo2010.ibge.gov.br/noticias?view=noticia\&id=1\&idnoticia $=363 \&$ busca $=1 \& \mathrm{t}=$ ibge-investigameio-ambiente-5-560-municipios-brasileiros. Acesso em 26 ago. 2006 e Anonymous. IBGE investiga o meio ambiente de 5.560 municipios brasileiros. Source: IPS. NoticiasFinancieras, Miami, p. 1, May 162005.

MARCONI, M. de A.; LAKATOS, E. M. Metodologia Científica. 4⿳a . ed. São Paulo: Editora Atlas, 2004.

MOURÃO, Renata Fernandes; SEO, Emília Satoshi Miyamaru. Logística reversa de lâmpadas fluorescentes. InterfacEHS. Revista de Saúde, Meio Ambiente e Sustentabilidade. V. 7, N. 3, 2012

Organização Pan-Americana da Saúde/Organização Mundial da Saúde (OPAS/OMS). Manual de Vigilância da Saúde de Populações Expostas a Agrotóxicos. Disponível em: < http://bvsms.saude.gov.br/bvs/publicacoes/livro2.pdf>. Acesso em: 01 jul. 2015.

SEHNEM, Simone; SIMIONI, Elisete; CHIESA, Jaqueline. Logística Reversa de Embalagens de Agrotóxicos e a Redução do Impacto Ambiental. Pretexto, Belo Horizonte, v. 10, n. 3, p. 47-60, $\mathrm{jul} / \mathrm{set} / 2009$ 
SHIBAO, Fábio Ytoshi; MOORI, Roberto Giro; SANTOS, Mário Roberto dos. A logística reversa e as embalagens vazias de defensivos agrícolas no Brasil. In: SIMPÓSIO DE ENGENHARIA DE PRODUÇÃO, XVIII, 2010, Bauru. Anais, São Paulo.

SOUZA, Valéria Nogueira de; GEBLER, Luciano. Análise de cenário envolvendo embalagens vazias de agrotóxicos originadas da cultura da macieira. Pesticidas: $R$. Ecotoxico e mio ambiente, Curitiba, v. 23, p. 75-82, jan/dez. 2013

VEZZALI, Fernanda. Opiniao-Avanço da soja eleva risco de contaminacão de trabalhadores no Piaui. Source: IPS. Noticias Financieras, Miami, p. 1, Jun 132006 e Carta Maior, Brasil, Set 072006. Disponível em <http://cartamaior.com.br/?/Editoria/Meio-Ambiente/Avanco-da-soja-eleva-risco-decontaminacao-de-trabalhadores-no-Piaui/3/10629>. Acesso em 26 ago.2016 